\title{
Measuring brand perceptions: Testing quantity and quality
}

Received (in revised form): 21st November, 2002

\section{Jenni Romaniuk}

is a Senior Research Fellow with the Marketing Science Centre, a research centre based at the University of South Australia. Her key research areas include brand image, salience and how brand perceptions influence buyer behaviour. She is also involved in measurement and strategic issues in brand research.

\section{Byron Sharp}

is Director of the Marketing Science Centre and Worldwide Director of the Centre's R\&D Initiative for Marketing. Participating companies, around the world, include Procter \& Gamble, Coca-Cola, General Motors, Commonwealth Bank of Australia, Unilever, AC Nielsen and many others.

\begin{abstract}
The image of a brand is considered to be important as is evident from the vast sums of money spent by companies on the development and measurement of their corporate/brand image. Yet very little is known about the relationship between brand perceptions and buyer behaviour. The authors empirically tested three hypotheses about the relationship between brand perceptions and loyalty. They found that (a) there was little evidence that any particular attributes are more related to customer loyalty than any others nor (b) that there were specific brand positions that were uniquely associated with higher loyalty. They did, however, find the more attributes associated with a brand the more loyal the customer. This is a relatively unexplored effect of brand perceptions, which should be included in brand tracking, and has some profound implications for marketing practice. It suggests that while distinctiveness is useful in making sure that the brand's marketing activities are noticed and correctly branded, the source of that distinctiveness is a less important marketing decision. Finally, they recommend that there should be different long and short-term goals for brand building. In the short term a choice may be made to focus on specific attributes. In the long term, however, marketers should work towards building the number of links between the brand and attributes in the market place, ie building the brand's share of mind.
\end{abstract}

Jenni Romaniuk Marketing Science Centre, University of South Australia, PO Box 2471, South Australia 5001.

Tel: +61 293809146 ; Fax: +61294750203 ; e-mail: Jenni.Romaniuk@ marketingsciencecentre.com

\section{INTRODUCTION}

The belief that brand perceptions strongly influence buying behaviour is widespread, and this belief underpins much of a business's marketing communication strategy. Firms look to image studies to explain current marketplace performance, eg numbers of units sold and price gained. It is common for particular positions (ie a particular combination of image attributes) to be chosen as desirable, thus leading to marketing objectives and subsequent advertising activities to 'reposition' the brand/firm. ${ }^{1,2}$ Firms also track changes in the proportion of respondents that hold particular perceptions about the firm/brand. 'Scores' on particular image perceptions are frequently built into managers' performance targets (key performance indicators). This practice assumes that 
these scores either indicate current or future market performance or that they actually cause current/future

performance. (The practice also assumes that these perceptual scores can be influenced by the managers in question.) This is because of the belief that the perceptions individual customers hold somehow affect their buying behaviour. Generally, it is held that the more positively the brand is perceived by the marketplace, the more customers will buy.

This paper investigates the relationship between brand image and customer loyalty and broadly asks the question: do customers who hold different perceptions exhibit different levels of loyalty? The concern here is with one type of loyalty, differentiation loyalty, which is the sensitivity of a customer to competing brands. This is operationalised as the customer's self-reported likelihood of defecting to a competing brand. ${ }^{3}$ The investigation reported here concerns a subscription market where sole brand loyalty is the norm (eg home loans, electricity supply) and so where buying another brand is an act of defection rather than being a part of a process of cycling through a repertoire of acceptable brands (such as occurs in grocery goods). ${ }^{4}$

Brand image: brand perceptions can come from a variety of sources, including consumer experiences, marketing communications and/or word of mouth. ${ }^{5}$ They can consist of descriptive information (eg comes in a blue carton), benefits (eg will not raise cholesterol), evaluations of specific aspects of the brand (eg provides excellent service) and/or purchase/consumption situations (eg a treat for the kids). ${ }^{6-8}$ Essentially, any information that is encountered with the brand name can, if sufficiently processed, become linked to the brand name in memory and thus become part of that brand's image.'

\section{BRAND IMAGE AND CUSTOMER LOYALTY}

The following section presents three theories regarding how brand perceptions can influence buyer behaviour. These theories have been developed drawing from relevant marketing, psychology and memory literature. From these are developed three hypotheses, which are subsequently tested. The ability to develop and test (potentially) competing hypotheses is a crucial aspect of this research. The use of competing hypotheses reduces the risk of confirmation bias. ${ }^{10,11}$

The first two hypotheses concern the 'quality' of the perceptions held of the brand, while the third hypothesis focuses on the quantity of perceptions devoted to the brand.

\section{Single attribute positioning}

It has been proposed that not all perceptions are as important as others, that there are certain perceptions that can operate as 'triggers' for purchase. That is, if a customer holds a specific belief/perception about the brand, they will buy it. Therefore, from a marketing perspective, there is benefit in getting more people to link the brand with that attribute. For example, if a customer thinks Sprint (brand) offers good value for money (perception), then largely irrespective of what else the customer thinks about Sprint, the customer is likely to purchase from that brand. ${ }^{12,13}$ This brand belief can be unique to the brand (ie I perceive Sprint is good value for money, but I do not perceive this about other brands) or relative to other brands (ie I believe that Sprint is better value for money than other brands). 
This theory implies that marketing managers should search for these 'triggers' and then develop campaigns focusing solely on those attributes. Traditionally, the scope for positioning was limited to different product category cues (ie offers home loans). More recent research, however, has shown that brands can be 'brought to (the consumer's) mind' via any number of image attributes. This can include situation attributes (eg at the beach), benefit attributes (eg is low in fat), country of origin attributes (eg is Italian) or quality attributes (eg is the best). All of these attributes have the potential to be triggers for someone buying the brand. ${ }^{14-16}$ So potentially any attribute linked to the brand could be a 'trigger' and therefore could be the most important message to communicate to the marketplace.

One test for the presence of these triggers is to see if there are any attributes where there is a greater link between perceiving that the brand has the quality represented by that attribute and future buying behaviour/loyalty towards the brand. If some attributes have a greater relationship with loyalty/future purchase than other attributes this would identify the attributes that would be suitable 'triggers' for the marketing manager to focus on in marketing communications. This leads to the first hypothesis:

H1: There are attributes (situations, benefits, quality etc) that are more strongly related to brand loyalty than other attributes.

\section{Multiattribute positioning}

To understand the relationships between brands and attributes in the marketplace, marketers often draw on multivariate analysis. This involves using techniques such as perceptual mapping, cluster analysis or factor analysis to identify attributes that are desirable for the brand to be associated with more than (a) other brands are and (b) other attributes. Similar to the first theory there is the idea that some positions are 'better' than others, in that they will lead to greater benefits for having that position than others. In contrast to the first theory, however, here positioning is based on clusters of attributes, which may be centred on a single theme (eg a brand seeking to build a relationship position may seek to be associated with attributes about likeability of staff and willingness of staff to listen and perceived interest in the customer's business and a business partner), or draw from a combination of different themes (eg being associated with attributes of excellent service, good value for money and a business partner). It has been argued that a unique mixture of strong associations is essential for a brand's success. ${ }^{17}$ There has been indirect empirical support for this whereby a unique set of attributes that were related to a brand being the primary store choice have been found. ${ }^{18}$

This theory is tested by 'playing marketing manager' and using a technique that, in the authors' experience, marketing managers generally use to determine the best position for their brand. This is through choosing bundles of desirable attributes. If a perceptual map displaying brands and attributes was developed from image survey data, managers would hope to see their brand positioned close to the cluster of these attributes. This was tested across customers to see if those who perceived the brand to have a particular position (ie would have those attributes clustered around the brand in their memory) had a higher loyalty level than those who did not perceive the brand to be in that position. A number of what appear at 
face value to be desirable positions were tested. The hypothesis is as follows:

H2: There will be specific clusters of attributes that will be related to higher loyalty to the brand.

\section{Brand salience/share of mind}

The third theory draws on a relatively small stream of research that has examined the role of the number of attributes associated with the brand and brand choice. This theory draws on the Associative Network Theories of Memory (ANT). ${ }^{19}$ ANT suggests that information in memory consist of concepts that are linked together in a network. Retrieval of information relies on the stimulus of a concept, which then activates connected nodes in a 'spreading activation' phenomenon. ${ }^{20}$ These links all have a chance of being retrieved at any point in time, but only a certain amount of information will be. ${ }^{21}$ In a buying context, these attributes have the potential to act and interact as retrieval cues or evaluation influencers in choice situations. ${ }^{22}$ Thus the more attributes to which the brand is linked, the greater the likelihood the brand will be retrieved and fit the criteria of interest to the customer, therefore chosen.

Some empirical support has emerged for this theory. In a series of experiments, a positive relationship has been found between the number of attributes associated with the brand, and subsequent choice of that brand. ${ }^{23}$ Other researchers who have examined quantity, rather than quality, of information have also found encouraging results. ${ }^{24}$ In some instances it has been suggested as an indicator of the strength of an overall attitude. The authors, however, take a more retrieval/memory theory approach and refer to this as a salience/share of mind measure. That is, the increasing links to attributes that could become brand retrieval cues (ie the brand's share of consumer mind) increases the probability of retrieval (ie greater brand salience). In contrast to the prior two theories, this places less emphasis on the nature/quality of the specific attributes/beliefs and more emphasis on the customer's propensity to mention the brand, of the quantity of information in memory. The attributes provided in any research are not meant to be all-inclusive, but rather sufficient to provide an indication of the brand's ability to be retrieved by the consumer. This leads to the final hypothesis:

H3: There will be a positive relationship between the number of image attributes the brand is associated with and loyalty to that brand.

\section{METHOD}

The market: the research was conducted in a subscription market (such as banking or insurance), where consumers' typically used only one brand for the service. In this instance the corporate brand and the brand under which customers buy the service are the same. In this context the use of an alternative provider constitutes 'defection' from the original brand, rather than cycling through a repertoire. ${ }^{25}$ As the sample was drawn from the total population, the sample sizes vary across brands according to their size in the marketplace. The specific sample sizes for each of the brands were 4,000 for Brand 1, 900 for Brand 2 and 350 for Brand 3. These three brands represent over 95 per cent of the total share of the market. The three brands are in direct competition with each other in the marketplace.

The respondents: the participants in the research were business users of a service who were screened to check they had influence over the selection of the 
supplier for this service. Respondents were contacted, recruited and interviewed via telephone by professional market research interviewers.

The attributes: both the ad agency and market research department of Brand 1 selected the brand image attributes. These were the attributes considered to be important in customer decision making. Details of the specific attributes are contained in the results section. They covered a variety of different aspects of brands that were perceived to be relevant to buyers in this market. This included facets such as pricing, service, expertise and relationship quality. The attributes were drawn from the market and effort was made to ensure that attributes relevant to all three brands (and not just one brand) were included.

The measures: image attribute responses were collected using a free choice, picking any format where both brands and perceptions are provided to respondents. ${ }^{26}$ That is, respondents were presented with an image attribute (eg 'tastes good') and asked which, if any, of the listed brands they associated with this attribute. This has been found to be a valid and reliable method of collecting perceptual data ${ }^{27}$ it is also commonly used in the market research industry. All attributes were positive and evaluative in nature. $^{28}$

Brand loyalty was captured using a derivative of the verbal probability scale, an 11-point probabilistic measure of brand switching. This is derived from the Juster scale for administration via telephone $\mathrm{e}^{29,30}$ and has been tested in terms of its reliability and validity and has also been shown to have a strong ability to predict future loyalty/defection behaviour. ${ }^{31}$ To make it a 'loyalty' indicator, the probability of switching was subtracted from the maximum of ten giving the probability of staying rather than leaving, ie being loyal was considered the inverse of the probability of defecting from the brand.

Respondents gave loyalty scores that ranged from nought to ten, ie, from no chance of staying with the brand through to 100 per cent chance of staying. Thus any of the image attributes perceptions had the potential to distinguish between highly loyal and very disloyal customers, however it turned out that no individual image attribute or even bundle of attributes has this much discriminatory power.

The questions regarding the image attributes and loyalty to the brand were separated by approximately five minutes of questions on other topics relevant to the market.

\section{Results for hypothesis 1: Single attributes}

Each image attribute for each brand was analysed by dividing respondents into two groups, (1) those who associated the brand with that attribute and (2) those who did not.

The difference in loyalty scores for each group by individual attribute for the three brands is shown in the Table 1.

ANOVA tests were used to determine if the differences in loyalty means between these two groups were statistically significant.

Examining Table 1, it is apparent that the majority of attributes/brand relationships coincide with a higher loyalty to the brand, though not much higher. None of the image attributes seem to act as a 'trigger' or major determinant of defection, so that those respondents who perceived the brand in this way are much less likely to defect. The mean loyalty difference between respondents who did and did not associate the brand with the attribute is only 0.6 , less than a single scale point 
Table 1: Difference in loyalty based on brand to attribute association

\begin{tabular}{lllll}
\hline & Brand 1 & Brand 2 & Brand 3 & Row Mean \\
\hline Economical & $1.1^{\star \star \star}$ & $0.8^{\star \star \star}$ & $1.1^{\star \star}$ & 1.0 \\
Good service & $0.8^{\star \star \star}$ & $0.7^{\star \star}$ & $1.4^{\star \star \star}$ & 1.0 \\
Cheap & $0.8^{\star \star \star}$ & $0.8^{\star \star}$ & $1.0^{\star \star}$ & 0.9 \\
Listens & $1.0^{\star \star \star}$ & $0.7^{\star \star}$ & $0.9^{\star \star \star}$ & 0.8 \\
Ahead & $0.7^{\star \star \star}$ & $0.7^{\star \star}$ & $1.0^{\star \star}$ & 0.8 \\
Easy to work with & $1.0^{\star \star \star}$ & $0.8^{\star \star \star}$ & 0.3 & 0.7 \\
Trustable & $0.8^{\star \star \star}$ & $0.6^{\star}$ & $0.8^{\star \star}$ & 0.7 \\
Thinks ahead & $0.8^{\star \star \star}$ & $0.4^{\star}$ & $0.7^{\star \star}$ & 0.6 \\
Smart & $0.8^{\star \star \star}$ & $0.4^{\star}$ & $0.6^{\star}$ & 0.6 \\
Knowledgeable & $0.8^{\star \star \star}$ & $0.7^{\star \star}$ & 0.4 & 0.6 \\
Solves problems & $0.6^{\star \star \star}$ & $0.6^{\star \star}$ & 0.5 & 0.6 \\
Helps & $0.5^{\star \star \star}$ & $0.7^{\star \star}$ & 0.5 & 0.6 \\
Works together & $0.8^{\star \star \star}$ & 0.4 & 0.5 & 0.5 \\
Cares & $0.8^{\star \star \star}$ & $0.4^{\star}$ & 0.2 & 0.5 \\
Responds & $0.8^{\star \star \star}$ & $0.4^{\star}$ & 0.3 & 0.5 \\
Important & $0.4^{\star \star \star}$ & $0.5^{\star \star}$ & 0.3 & 0.4 \\
Worthwhile & $0.7^{\star \star \star}$ & 0.1 & 0.2 & 0.3 \\
Insights & $0.6^{\star \star \star}$ & 0.4 & 0.0 & 0.3 \\
Column mean & 0.8 & 0.6 & 0.6 & 0.6 \\
\hline${ }^{\star \star *}=p<0.001,{ }^{* \star}=p<0.01,{ }^{*}=p<0.05$ & & &
\end{tabular}

(and 6 per cent difference in defection probability). There is more variation between attributes (0.4 to 1.0$)$ than between brands ( 0.8 to 0.6 ) but neither varies dramatically from the overall mean. There are some attributes that have a higher difference than other attributes, but these seem to encompass a group of about 6 or 7 attributes, and these groups of attributes are the same for all three brands. So, while association with a brand attribute is positive, in absolute quantitative terms there appear to be minimal differences between brands. So, while it is possible to identify attributes which have a stronger relationship with loyalty, it is difficult to isolate a specific attribute for each brand that would be dramatically better than any other attribute for that brand, or would not also be suitable for other brands in the market.

This provides some limited empirical support for Hypothesis 1. Some attributes do seem a tiny bit more associated with loyalty than others.

Of course this does not preclude the possibility that the key drivers are attributes other than those included in the study. Given, however, that people knowledgeable about the market and the brands chose the attributes it seems unlikely that any other attributes would provide dramatically different results.

\section{Results for hypothesis 2: Multiattribute positioning}

To test this hypothesis a series of 'multiattribute positions' (combinations of up to four attributes) were examined. If there is a relationship between having a particular 'position' and loyalty a greater positive difference in loyalty would be expected if a customer perceives a brand in this 'position' (ie has all of these attributes) than if it is not. The following eight positions were tested. The first five are centred around a single theme, while the final three were combinations of different themes: ${ }^{32}$

- service based (three attributes)

- expertise based (three attributes)

- information/solution based (three attributes)

- relationship based (three attributes)

— pricing based (two attributes) 
Table 2: Multiattribute positions and loyalty

\begin{tabular}{llll}
\hline & Brand 1 & Brand 2 & Brand 3 \\
\hline Combination 2 & $1.9^{\star \star \star}$ & $1.2^{\star \star \star}$ & 0.7 \\
Combination 1 & $1.8^{\star \star \star}$ & $1.7^{\star \star \star}$ & $2.1^{\star \star \star}$ \\
Combination 3 & $1.7^{\star \star \star}$ & $1.4^{\star \star \star}$ & $1.5^{\star \star \star}$ \\
Service & $1.7^{\star \star \star}$ & $1.2^{\star \star \star}$ & $1.7^{\star \star \star}$ \\
Relationship & $1.6^{\star \star \star}$ & $1.2^{\star \star \star}$ & $1.0 \#$ \\
Information/Solution & $1.5^{\star \star \star}$ & $1.0^{\star \star}$ & $1.1^{\star \star}$ \\
Expertise & $1.4^{\star \star \star}$ & $1.6^{\star \star \star}$ & $1.0 \#$ \\
Pricing & $1.3^{\star \star \star}$ & $1.1^{\star \star \star}$ & $1.4^{\star \star \star}$ \\
\hline
\end{tabular}

$\# p<0.10,{ }^{\star *} p<0.01,{ }^{\star \star \star} p<0.001$

- combination 1 (value, service, expertise and listening)

- combination 2 (proactive, price competitiveness, partnership and ease of working together)

- combination 3 (responsive, understanding, solutions and value).

As previously mentioned, loyalty is measured on a $0-10$ scale. For each brand and position the loyalty of customers who perceived the brand to be associated with all of the attributes in the position was compared with the loyalty of customers who did not perceive the brand to be associated with any of the attributes in the position. For example, if those who perceived the brand in that position had a loyalty of 8.4 and those who did not perceive the brand to be in that position had a loyalty of 6.4 , the difference would be 2.0 scale points. It is this difference in loyalty that is shown in Table 2.

Examining the results across all brands, the difference in loyalty ranges from 0.7 to 2.1; however, for most brands on most positions the difference is about 1.5 (15 per cent difference in loyalty between those who did associate the brand for all the attributes in the cluster and those who did not).

While it is possible to identify a position with the greatest difference in loyalty for each brand, the difference between that position and others looks to be minimal (they are all very close to the mean score of 1.5). No brand seems to have an ideal position for its customer base. Of course, this is a subjective assessment, but it would be a tall order to argue that any difference is meaningful. From a marketing management perspective, based on these results, there is little justification for any brand for choosing one position over another.

\section{Results for hypothesis 3: Brand salience/share of mind}

To test Hypothesis 3, a calculation was made of the number of times the brand was mentioned across all of the attributes presented to the respondent. This is referred to as the brand salience. This ranged from zero times (the brand not mentioned for any of the attributes) to mentioning the brand up to 19 times (the brand mentioned for all attributes). The mean loyalty at each level of brand salience was calculated and revealed a positive relationship between the number of attributes the brand was associated with and loyalty. Brand loyalty was measured on a $0-10$ scale, which is the range (shown on the y axis). This provides support for Hypothesis 3. Figure 1 shows this relationship.

Further examining Figure 1, it is evident that this relationship is also relatively consistent between brands, 


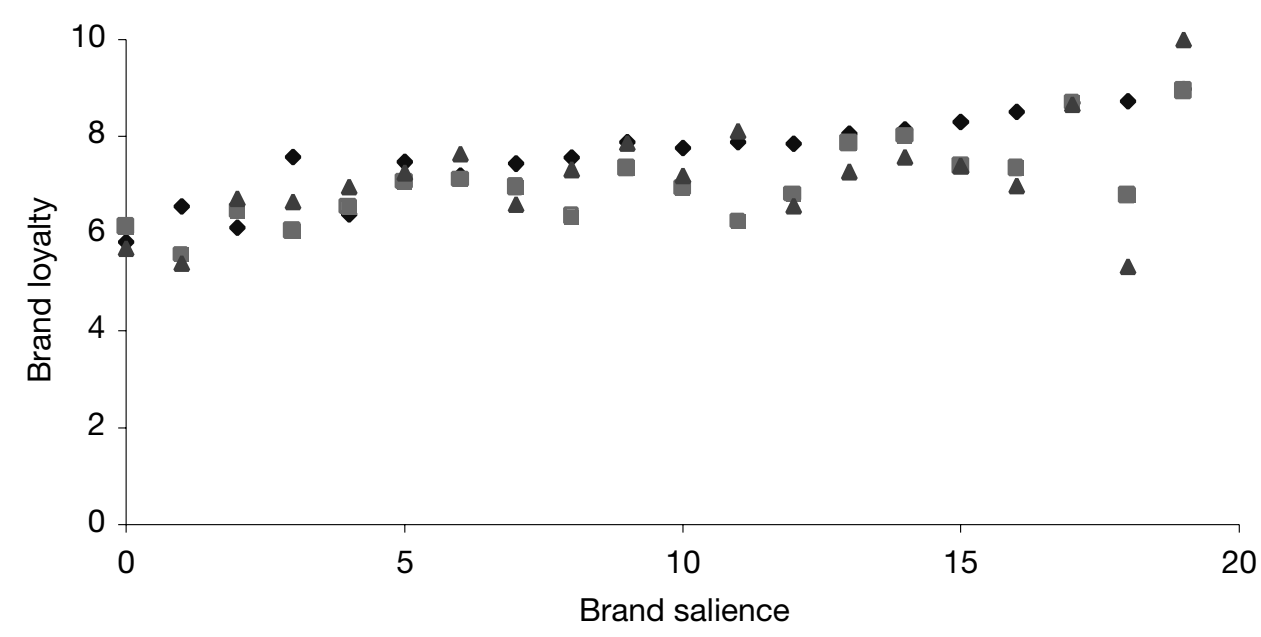

- Brand 1 Brand $2 \triangle$ Brand 3

Figure 1 Brand salience and brand loyalty

Table 3: Regression results

\begin{tabular}{llll}
\hline & Adj. $\boldsymbol{r}$-squared & $\boldsymbol{b}$-value & Constant \\
\hline Brand 1 & 0.82 & 0.14 & 6.2 \\
Brand 2 & 0.57 & 0.11 & 5.9 \\
Brand 3 & 0.45 & 0.09 & 6.2 \\
\hline
\end{tabular}

particularly when sample size is taken into account (the brands with the most variability are the smaller sample size brands).

To quantify the relationship between the two variables, regression at the aggregate level was undertaken, ie the data points in Figure 1 (see Table 3). A relatively consistent relationship between perceptions and loyalty across brands was evident. The baseline loyalty is approximately six out of ten. Each additional time a brand is mentioned as a perceptual response, the loyalty increases by about 0.1 points out of ten. It is also possible to see a slight brand size effect, with the incremental increase in loyalty for each additional brand mention increasing as brand size increases. Given the large difference in the number of users for each brand, the difference in B values is, however, relatively minor.
This consistent linear relationship also explains the lack of variation found between attributes and positions in testing the single and multiple attribute positioning theories.

\section{DISCUSSION}

An overall assessment of the analysis appears to fail to support the view that there are particular brand perceptions, or combinations of perceptions/positions, that are more (or even less) associated with loyalty. Instead a consistent linear association is shown between the number of image attributes that a respondent associates the brand with and their loyalty to that brand. And this is enough to explain why clusters of attributes did better at distinguishing between loyal customers and those vulnerable to defect - simply because to mention all the 
attributes in a cluster meant a respondent was mentioning the brand more.

The total number of times a brand is mentioned by respondents in an image survey is a relatively ignored method of measuring brand performance that appears to warrant inclusion in any tool to assess brand image.

These findings support firms undertaking market research into brand image/perceptions because it is important for a brand to be well known by its customer base. These findings suggest, however, that it is less important specifically how the brand is perceived at any one point in time (so long as it is vaguely positive). That is, brand managers should not be concerned if customers think of the firm as offering competitive prices, good service or experts in the field, just as long as they know something about the firm - and the more the better.

This finding does fit in with what is understood about how consumers hold information about brands. That is, in the form of an associative network ${ }^{33}$ where the brand name is linked to relevant attributes. This provides the mechanism for retrieval for brands in choice situations. Consumers use these attributes as retrieval cues for accessing choice information. Therefore, it seems the greater the share of mind (regardless of the attributes actually linked to the brand name) the more loyal the customer.

It could be argued that the multiattribute measure used here is simply a crude measure of attitude in the form of a sum of the beliefs a customer holds about the brand. ${ }^{34}$ Therefore, it is the strength of the attitude to the brand that is related to future behaviour. This is a possibility that needs further empirical testing to distinguish clearly between a 'salience/retrieval' and an 'attitudinal' perspective for interpreting the empirical results presented here. The results of this paper do suggest, however, that further testing to see if the basis of this relationship is salience, attitude or some combination of the two would be a useful endeavour to improve understanding of how consumer perceptions influence future behaviour.

It is also worth noting that these results complement that of past research, which found (despite aggregate stability) a systematic instability in the association of specific attributes with specific brands at individual level. ${ }^{35}$ Systematic instability of brand mention at individual level calls into question the ability of a specific brand/attribute link to be crucial in the future purchase decision.

\section{IMPLICATIONS}

It is suggested that marketers should be looking to maintain and increase the salience of their brands in the minds of customers; that is, to develop and reinforce the breadth of the network about the brand in consumer memory. This takes the focus away from specifically what attributes customers associate with brands and towards how many attributes customers associate with brands. This provides greater scope for variation of the messages sent out to customers, which should provide more opportunities to create entertaining and useful advertising.

Techniques such as perceptual mapping may be used as a stimulus for new ideas about creative advertising content. Indeed the results here highlight a benefit of perceptual mapping and image analysis, that is, identification of attributes that the brand is not currently associated with. If the objective is to ensure that customers link the brand with as many (non-negative) attributes as possible, then it is necessary to identify those attributes where improvement is possible.

The results of this research also suggest a new way to measure the performance 
of a brand, through measuring the share of mind' it holds, or brand salience.

There are several implications for measurement. The first is that this finding calls into question the practice of undertaking brand image studies that seek to identify and recommend the best position in the marketplace. It is difficult to see on what basis it can legitimately be claimed that one position is superior to another, since the position in itself does not seem to be related to a higher loyalty level. The second aspect is that the results also question the practice of monitoring a few 'key' perceptions, eg with line charts and including these as key performance indicators. Usually, such a practice is based on the assumption that some attributes are particularly important in influencing buyer behaviour. This research has found this assumption to be unsupported. The best case that can be made is for all attributes to be monitored so that an overall assessment of brand performance can be made.

The findings should also not be interpreted as suggesting that the ideal position on a correspondence analysis based perceptual map is in the centre. While it appears that it is desirable to be associated with as many image attributes as possible such a result would not necessarily give a central position. It is suggested that it is important to have a specific position, which can be any (non-negative) position, so long as it is distinct. A distinct position does not mean that buyers will be dramatically more loyal to the brand. There are, however, other benefits of being distinctive that are not covered in this research. For example, it may facilitate the clear (and easily recognisable) branding of marketing communications and give consumers something by which they can easily categorise and remember the brand. Thus increasing the effectiveness of marketing communications at obtaining 'cut through'.

\section{Strategic brand management}

There are, the authors suggest, two distinct objectives for short-term and long-term brand building. In the short term, managers need to identify a specific attribute or position for communication to the market. The similarity in results across multiple attributes suggests that the specific attribute for a short-term focus can be chosen based on which message provides the best creative execution. The key aim is to develop likeable adverts, so that cut through in the marketplace can be achieved. An important note is that even if a manager was to take the attributes with the strongest relationship with loyalty, these are likely to be the same attributes that competitors would consider to be attractive for positioning as well. This makes it particularly important to ensure that any marketing communications are prominently and distinctly branded. This makes it easier for customers to know who is advertising.

In the long term, the objective is to build up the 'bank' of perceptions that consumers hold about the brand. This gradual accumulation of attributes builds the 'share of mind' for the brand, making it (a) the one that will be thought of and (b) more difficult for competitors to have access to the mind of customers. This suggests that there might be value in advertising counter to the brand's current position, a tactic at odds with 'positioning theory' recommendations. ${ }^{36}$ This seems a worthy area for research.

\section{Limitations and future research}

Finally, it is stressed that the authors have investigated the relationship between image and only one aspect of 
buyer behaviour (loyalty), albeit an extremely important one. The results do not preclude other links between particular perceptions or combinations of perceptions and behaviour. For example, customers who perceive a brand to be very high quality may be willing to pay more for this brand, or particular positions may be beneficial for acquiring customers (the research here deals solely with the retention of existing customers). This is an important area for future research. Additionally it may be that the level of importance of the attribute moderates the effect of that attribute for a specific consumer. That the effects across the whole market seem to cancel each other out suggests, however, that importance, if it is a factor, is not a very influential one at aggregate level. It may, however, have important implications at individual level and so should be investigated.

Replication and extension across a wide range of markets and conditions are recommended, to test the generalisability of these findings - particularly to other types of markets, such as fast moving consumer goods markets. This is particularly so given the research of Low and Lamb ${ }^{37}$ which suggested that there would be variation in results across product categories, in line with changes to brand familiarity structures.

Finally, it is suggested that research into the effect of advertising on brand salience would be useful, so that marketers can understand to what extent they can influence memory structures in the short term.

\section{References}

1 Ries, A. and Trout, J. (1981) 'Positioning the battle for your mind', McGraw-Hill Inc, New York.

2 Aaker, D. A. and Shansby, G. (1982) 'Positioning your product', Business Horizons, Vol. 25, pp. 56-62.

3 Sharp, B., Rundle-Thiele, S. and Dawes, J. (1997)
'Three conceptualisations of loyalty', Australia New Zealand Marketing Educators Conference 97, Department of Marketing, Monash University, Melbourne.

4 Sharp, B. and Wright, M. (1999) 'There are two types of repeat purchase markets', 28th European Marketing Academy Conference, Institute of Marketing, Humboldt-University, Berlin, Germany.

5 Krishnan, H. S. (1996) 'Characteristics of memory associations: A consumer-based brand equity perspective', International Journal of Research in Marketing, Vol. 13, pp. 389-405.

6 Joyce, T. (1963) 'Techniques of brand image measurement', New Developments in Research, Market Research Society, London, pp. 45-63.

7 Barwise, T. P. and Ehrenberg, A. S. C. (1985) 'Consumer beliefs and brand usage', Journal of the Market Research Society, Vol. 27, No. 2, pp. 81-93.

8 Aaker, D. A. (1991) 'Managing brand equity: Capitalizing on the value of a brand name', The Free Press, New York.

9 Keller, K. L. (1993) 'Conceptualizing, measuring, and managing customer-based brand equity', Journal of Marketing, Vol. 57, January, pp. 1-22.

10 Greenwald, A. G., Pratkanis, A. R., Leippe, M. R. and Baumgardner, M. H. (1986) 'Under what conditions does theory obstruct research progress?', Psychological Review, Vol. 93, No. 2, pp. 216-229.

11 Wright, M. and Kearns, Z. (1998) 'Progress in marketing knowledge', Journal of Empirical Generalisations in Marketing Science, Vol. 3, pp. 1-21.

12 Alpert, M. I. (1971) 'Identification of determinant attributes: A comparison of methods', Journal of Marketing Research, Vol. 8, May, pp. 184-191.

13 Woodside, A. G. and Trappey, R. J. (1992) 'Finding out why customers shop in your store and buy your brand: Automatic cognitive processing models of primary choice', Journal of Advertising Research, Vol. 32, pp. 59-78.

14 Rossiter, J. R. and Percy, L. (1987) 'Advertising and promotion management', McGraw-Hill, Singapore.

15 Holden, S. J. S. (1993) 'Understanding brand awareness: Let me give you a c(l)ue!', Advances in Consumer Research, Vol. 20, pp. 383-388.

16 Holden, S. J. S. and Lutz, R. J. (1992) 'Ask not what the brand can evoke; Ask what can evoke the brand?', Advances in Consumer Research, Vol. 19, pp. 101-107.

17 Grant, M, and Opie, T. (2001) 'Making more than a difference', Admap, April, WARC, Henley-on-Thames.

18 Thelen, E. and Woodside, A. G. (1997) 'What evokes the brand or store? Consumer research on accessibility theory applied to modelling primary choice', International Journal of Research in Marketing, Vol. 14, pp. 125-145.

19 Anderson, J. R. and Bower, G. H. (1979) 'Human associative memory', Lawrence Erlbaum, Hillsdale, NJ.

20 Collins, A. M. and Loftus, E. F. (1975) 'A spreading activation theory of semantic processing', Psychological Review, Vol. 82, No. 6, pp. 407-428. 
21 Raaijmakers, J. G. W. and Shiffrin, R. M. (1981) 'Search of associative memory', Psychological Review, Vol. 88, No. 2, pp. 93-134.

22 Holden (1993) op. cit.

23 Alba, J. W. and Marmorstein, H. (1987) 'The effects of frequency knowledge on consumer decision making', Journal of Consumer Research, Vol. 14, pp. 14-25.

24 Krishnan (1996) op. cit.

25 Sharp and Wright (1999) op. cit

26 Holbrook, M. B., Moore, W. L. and Winer, R. (1982) 'Constructing joint spaces from pick-any data: A new tool for consumer analysis', Journal of Consumer Research, Vol. 9, June, pp. 99-105.

27 Barnard, N. R. and Ehrenberg, A. S. C. (1990) 'Robust measures of consumer brand beliefs', Journal of Marketing Research, Vol. 27, November, pp. 477-487.

28 In line with Barwise, T. P. and Ehrenberg, A. S. C. (1987) 'Consumer beliefs and awareness', Journal of the Market Research Society, Vol. 29, No. 1, pp. 88-94.

29 Juster, F. T. (1960) 'Prediction and consumer buying intentions', American Economic Review, Vol. 50, pp. 604-622.

30 Brennan, M., Esslemont, D. and Hini, D. (1995)
'Obtaining purchase predictions via telephone interviews', Journal of the Market Research Society, Vol. 37, No. 3, pp. 241-250.

31 Danenberg, N. and Sharp, B. (1996) 'Measuring loyalty in subscription markets using probabilistic estimates of switching behaviour', Australia New Zealand Marketing Educators Conference, Department of Marketing, University of Auckland, Auckland, NZ.

32 In line with Grant and Opie (2001) op. cit.

33 Anderson and Bower (1979) op. cit.

34 Fishbein, M. and Ajzen, I. (1975) 'Belief, attitude, intention and behaviour: An introduction to theory and research', Addison-Wesley Publishing Company, Reading, Massachusetts.

35 Dall'Olmo Riley, F, Ehrenberg, A. S. C., Castleberry, S. B., Barwise, T. P. and Barnard, N. R. (1997) 'The variability of attitudinal repeat-rates', International Journal of Research in Marketing, Vol. 14, No. 5, pp. 437-450.

36 Ries and Trout (1981) op. cit.

37 Low, G. S. and Lamb, C. W. (2000) 'The measurement \& dimensionality of brand associations', Journal of Brand and Product Management, Vol. 9, No. 6, pp. 350-368. 